\title{
Níveis de Proteína em Suplementos para Terminação de Bovinos em Pastejo Durante o Período de Transição Seca/Águas: Consumo Voluntário e Trânsito de Partículas
}

\author{
Edenio Detmann ${ }^{1}$, Mário Fonseca Paulino², Paulo Roberto Cecon ${ }^{3}$, Sebastião de Campos \\ Valadares Filho ${ }^{4}$, Joanis Tilemahos Zervoudakis ${ }^{5}$, Luciano da Silva Cabral ${ }^{5}$, Maria Ignês Leão ${ }^{6}$, \\ Rogério de Paula Lana ${ }^{7}$, Niraldo José Ponciano ${ }^{8}$
}

\begin{abstract}
RESUMO - Avaliaram-se o consumo e os parâmetros da cinética de trânsito de partículas em bovinos suplementados durante a fase de transição entre os períodos seco e chuvoso. Foram utilizados cinco novilhos Holandês x Zebu com idade e peso médios iniciais de 24 meses e $304 \mathrm{~kg}$, respectivamente, manejados em cinco piquetes de Brachiaria decumbens (0,34 ha). Foram fornecidos suplementos (4 kg/animal/dia), constituídos por fubá de milho, grão de soja integral, uréia, sulfato de amônia e mistura mineral, formulados para apresentarem níveis de 12,16, 20 e 24\% de proteína bruta (PB), com base na matéria natural. O experimento foi conduzido em quatro períodos experimentais de 21 dias e analisado por delineamento em quadrado latino 4 x 4 . O quinto animal, mantido sem suplementação (controle), foi utilizado como medida de comparação descritiva. A forragem selecionada pelos animais apresentou teores médios de PB e fibra em detergente neutro (FDN) de 109,9 e 564,4 g/kg de matéria seca (MS), respectivamente. A variação do nível de PB dos suplementos não alterou os consumos de MS, de matéria orgânica e de FDN. O fornecimento de suplementos reduziu o consumo de pastagem e ampliou o consumo de MS total em relação ao controle, com coeficiente médio de substituição de 0,41. O nível de PB dos suplementos não afetou a taxa de passagem ruminal das partículas, cujo valor médio $\left(0,034 \mathrm{~h}^{-1}\right)$, foi superior ao observado no controle $\left(0,029 \mathrm{~h}^{-1}\right)$.
\end{abstract}

Palavras-chave: capim-braquiária, compostos nitrogenados, pastagens tropicais, suplementação protéica

\section{Effects of Feeding Different Protein Levels of Supplements to Finishing Cattle in Pasture During the Dry to Rainy Transition Season on Voluntary Intake and Passage of Particles}

\begin{abstract}
The objective of this trial was to evaluate the voluntary intake and ruminal passage of particles in supplemented finishing cattle during the drought to rainy transition season. Five Holstein x Zebu steers averaging $304 \mathrm{~kg}$ of live weight and 24 months of age located in five paddocks (0.34 ha each) of Brachiaria decumbens were used in this trial. The supplements fed (4 kg/ animal/day) contained ground corn, whole soybean, urea, ammonium sulfate, and minerals and were formulated to yield, on as-fed basis, $12,16,20$, and $24 \%$ of crude protein (CP). Four animals were assigned to a $4 \mathrm{x} 4$ Latin square with experimental periods lasting 21 days. The remaining animal was not supplemented and was used for comparative purposes (CONT). Forage grazed by the animals had average contents of CP and neutral detergent fiber (NDF) of 109.9 and $564.4 \mathrm{~g} / \mathrm{kg}$ of dry matter (DM), respectively. No significant differences in the intakes of DM, organic matter, and NDF were observed by increasing the CP contents of the supplements. Supplementation reduced consumption of forage but total DM intake was greater in the supplemented than in the CONT animal. Increasing the CP content of the supplements did not change the ruminal passage rate of particles that averaged $0.034 \mathrm{~h}^{-1}$ for the supplemented steers and was higher than that of the CONT animal $\left(0.029 \mathrm{~h}^{-1}\right)$.
\end{abstract}

Key Words: nitrogenous compounds, signalgrass, protein supplementation, tropical pastures

\section{Introdução}

A produção de carne bovina no Brasil baseia-se na exploração de pastagens, que respondem por cerca de $95 \%$ do ganho total de peso dos animais abatidos anualmente (Zimmer \& Euclides Filho, 1997). Entre os diferentes centros de produção, destaca-se a região central brasileira, caracterizada por duas grandes estações climáticas, distintas principalmente quanto ao nível de precipitação, comumente denominadas

\footnotetext{
1 Zootecnista, D.Sc., Professor Adjunto, Departamento de Zootecnia, Universidade Federal de Viçosa, Viçosa-MG, 36571-000, Bolsista do CNPq (detmann@ufv.br).

2 Eng ${ }^{\circ}$. Agrônomo, D.Sc., Professor Adjunto, DZO-UFV, Bolsista do CNPq.

3 Eng ${ }^{\circ}$. Agrônomo, D.Sc., Professor Adjunto, Departamento de Informática, UFV, Bolsista do CNPq.

4 Zootecnista, D.Sc., Professor Titular, DZO-UFV, Bolsista do CNPq.

5 Zootecnista, D.Sc., Professor Adjunto, Universidade Federal de Mato Grosso, Cuiabá-MT.

6 Médica Veterinária, D.Sc., Professora Titular, DZO-UFV.

7 Zootecnista, Ph.D., Professor Adjunto, DZO-UFV, Bolsista do CNPq.

8 Eng ${ }^{\circ}$. Agrônomo, D.Sc., Professor Associado, Universidade Estadual do Norte Fluminense, Campos dos Goytacazes-RJ.
} 
período seco e período chuvoso ou das águas, que impõem características peculiares às forrageiras sob pastejo.

Durante o período seco, as forrageiras decrescem rapidamente em digestibilidade e, particularmente, em conteúdo total de compostos nitrogenados, o que acarreta perdas de peso aos animais, constituindo o principal fator limitante à produção (Leng, 1984). Durante o período de chuvas, embora as pastagens não sejam consideradas deficientes em proteína bruta, os ganhos de peso obtidos estão aquém daqueles observados sob condições similares em regiões temperadas. Essa discrepância pode ser, em parte, atribuída à alta degradabilidade da proteína bruta da forragem, o que provoca perda excessiva de compostos nitrogenados no ambiente ruminal na forma de amônia, gerando déficit protéico em relação às exigências para ganhos elevados (Poppi \& McLennan, 1995). Embora as deficiências nutricionais, em ambos os períodos, estejam relacionadas principalmente à proteína, a mudança de estação seca para a chuvosa altera o enfoque dado a essa deficiência, transformando-a de dietética em metabólica.

Em sistemas de terminação de bovinos em pastejo durante o período seco, níveis elevados de suplementos, em torno de 0,8 a $1,0 \%$ do peso vivo (PV), são fornecidos almejando-se ganhos superiores a $0,8 \mathrm{~kg} /$ dia. Contudo, adiamento na data de abate dos animais ou antecipação do início das chuvas constituem eventos de possível ocorrência. Sob tais circunstâncias, a composição da forragem disponível ao pastejo alterase rapidamente, devendo-se adequar, conjuntamente, a formulação dos suplementos fornecidos, principalmente quanto à composição protéica.

Os objetivos neste trabalho foram avaliar os efeitos de diferentes níveis de proteína bruta (PB) em suplementos múltiplos para terminação de bovinos mestiços em pastagem de Brachiaria decumbens, durante a fase de transição entre os períodos seco e chuvoso sobre os consumos de matéria seca (MS) total, de MS da forragem, de matéria orgânica (MO) total, de MO da forragem, de fibra em detergente neutro (FDN), de PB e de carboidratos totais (CT) e não-fibrosos (CNF), e sobre os parâmetros da cinética de trânsito gastrintestinal de partículas.

\section{Material e Métodos}

O experimento foi realizado no município de Capinópolis, localizado na macro-região do Pontal do Triângulo no Estado de Minas Gerais.
A área experimental consistiu de cinco piquetes de 0,34 hectares cada, formados uniformemente com a gramínea Brachiaria decumbens Stapf. e providos de bebedouro e comedouro.

Avaliaram-se suplementos constituídos por fubá de milho, soja grão integral, uréia, sulfato de amônia e mistura mineral, balanceados, segundo análise prévia, para apresentarem os níveis de 12, 16, 20 e 24\% PB, com base na matéria natural, correspondentes aos tratamentos S12, S16, S20 e S24, respectivamente. Fixou-se em 3:1 a relação entre os compostos nitrogenados oriundos de alimentos concentrados e aqueles fornecidos pela mistura uréia/sulfato de amônia (9:1). Os suplementos foram fornecidos, diariamente, na quantidade de $4 \mathrm{~kg} /$ animal às $10 \mathrm{~h}$, proporcionando-se livre acesso à água e à mistura mineral, em todos os tratamentos. No tratamento controle (SAL), forneceu-se exclusivamente mistura mineral. A composição dos suplementos é mostrada na Tabela 1.

Foram utilizados cinco novilhos $1 / 2$ holandês $x$ zebu, não-castradoscom idade e peso médios iniciais de 24 meses e $304 \mathrm{~kg}$, fistulados no esôfago, rúmem e abomaso.

O experimento constou de quatro períodos experimentais, conduzidos entre agosto e novembro de 2000, com duração de 21 dias cada, sendo os sete primeiros destinados à adaptação dos animais. Os dados climáticos em função dos diferentes períodos experimentais são apresentados na Tabela 2.

Ao terceiro dia de cada período experimental, realizou-se coleta da massa forrageira disponível na pastagem através do corte, rente ao solo, de cinco áreas delimitadas por um quadrado metálico de $0,5 \mathrm{x}$ $0,5 \mathrm{~m}$, escolhidas aleatoriamente dentro de cada piquete. Após a pesagem, as amostras foram homogeneizadas por piquete, retirando-se uma alíquota que foi destinada à avaliação do teor de MS (AOAC, 1990). Constam na Tabela 2 as disponibilidades de matéria seca, em função dos períodos experimentais.

A avaliação da composição da dieta ingerida pelos animais foi realizada no 50 e no $21^{\circ}$ dia de cada período experimental a partir de amostras de extrusa esofágica. Às $20 \mathrm{~h}$ do dia anterior, os animais foram recolhidos ao curral de contenção, localizado nas proximidades dos piquetes experimentais, de forma a permitir jejum prévio de aproximadamente 12 horas, com o intuito de evitar possíveis problemas quanto à regurgitação durante a coleta. Às $8 \mathrm{~h}$, os animais foram equipados com bolsas coletoras de fundo telado acopladas abaixo da fístula esofágica e conduzidos a 
Tabela 1 - Composição alimentar percentual, níveis de proteína bruta (PB), proteína degradável no rúmen (PDR) e nutrientes digestíveis totais (NDT) dos suplementos, com base na matéria natural

Table 1 - Feed composition, crude protein (CP), rumen-degradable protein (RDP) and total digestible nutrients (TDN) of the supplements, as-fed basis

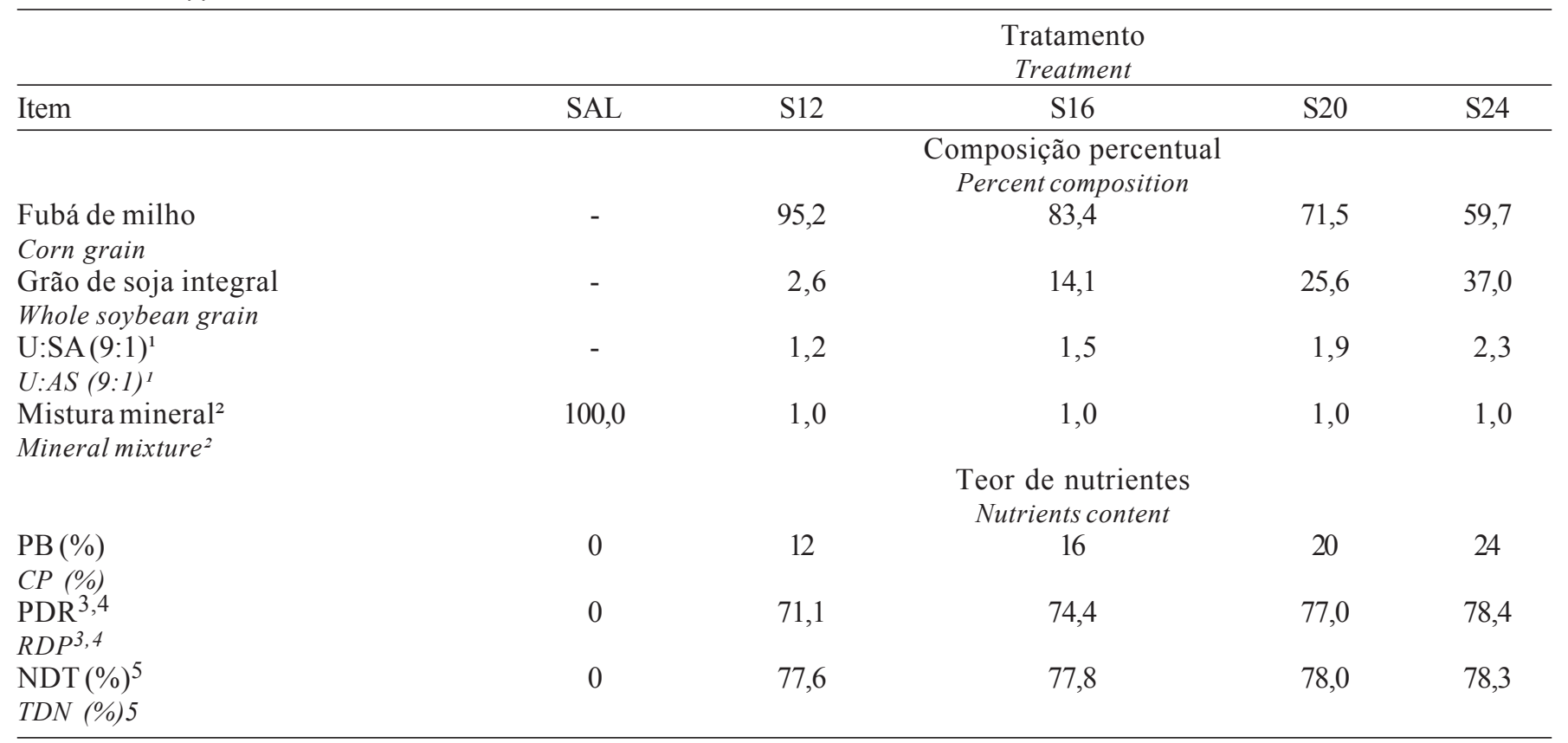

1 U:SA - uréia: sulfato de amônia.

2 Composição percentual: fosfato bicálcico, 48,61; cloreto de sódio, 48,61; sulfato de zinco, 1,46; sulfato de cobre, 0,72; sulfato de magnésio, 0,50; sulfato de cobalto, 0,05; e iodato de potássio, 0,05.

$3 \%$ da PB $(\% \mathrm{CP})$.

${ }^{4}$ Determinado segundo estimativas de parâmetros de degradação ruminal relatadas por NRC (2001), pressupondo-se taxa de passagem de $0,05 \mathrm{~h}^{-1}$.

5 Estimado segundo NRC (1984).

1 U:AS - urea: ammonium sulfate.

${ }^{2}$ Composition (\%): dicalcium phosphate, 48.61; sodium chlorine, 48.61; zinc sulfate, 1.46; copper sulfate, 0.72; magnesium sulfate, 0.50; cobalt sulfate, 0.05; potassium iodine, 0.05 .

${ }^{4}$ Obtained according to the NRC (2001) model, assuming a rate of passage of $0.05 h^{-1}$

5 It was estimated according to teh NRC (1984) model.

Tabela 2 - Precipitação total (PP), temperaturas médias máxima (Tmax) e mínima (Tmin) e disponibilidade total de forragem (DTF) na pastagem de acordo com os períodos experimentais

Table 2 - Total rainfall (TR), highest (Th) and lowest (TI) average temperatures, and total available forage (TFA) in each experimental period

\begin{tabular}{lcccc}
\hline & \multicolumn{4}{c}{$\begin{array}{c}\text { Período experimental } \\
\text { Experimental period }\end{array}$} \\
\cline { 2 - 5 } Item & 1 & 2 & 3 & 4 \\
\hline $\mathrm{PP}^{1}$ & 43,7 & 14,4 & 10,9 & 43,7 \\
$T R^{1}$ & 30,7 & 31,1 & 35,2 & 32,6 \\
$\operatorname{Tmax}^{2}$ & 17,8 & 19,5 & 20,8 & 21,1 \\
$T^{2}$ & 5,93 & 6,30 & 6,37 & 3,40 \\
$\operatorname{Tmin}^{2}$ & & & & \\
$T l^{2}$ & & &
\end{tabular}

seus respectivos piquetes, onde pastejaram livremente por cerca de 40 minutos, sendo, então, recolhidos para retirada das bolsas e reconduzidos à área de pastejo. As amostras de extrusa foram colocadas em sacos plásticos, identificadas e congeladas a $-20^{\circ} \mathrm{C}$.

A estimação da excreção fecal e da cinética de trânsito de partículas baseou-se no fornecimento, dose única, de cromo mordente à fibra, produzido conforme descrição de Udén et al. (1980). A base fibrosa para produção do indicador foi retirada de amostras de simulação manual de pastejo, obtidas entre o $5^{\circ}$ e o $10^{\circ}$ dia de cada período experimental. Para simulação do processo inicial de mastigação, as amostras de pastejo simulado foram submetidas a um processo tríplice de moagem em moinho tipo Willey, sem 
a presença de peneira. Foram fornecidos, por animal, $100 \mathrm{~g}$ de fibra mordente no 16 o dia do período experimental, às $8 \mathrm{~h}$. As amostras fecais foram tomadas nos tempos $0,6,12,18,24,30,36,42,48,60,84,108$ e 144 horas após o fornecimento do indicador (Detmann et al., 2001a), sendo, posteriormente, secas em estufa de ventilação forçada a $60^{\circ} \mathrm{C}$ ( 72 horas), processadas em moinho tipo Willey ( $1 \mathrm{~mm}$ ) e acondicionadas individualmente em frascos de polietileno. Posteriormente, retiraram-se, de cada amostra, alíquotas de $3 \mathrm{~g}$, produzindo-se amostras compostas por animal/período.

As amostras de fezes e fibra mordente foram analisadas individualmente quanto aos teores de matéria seca (AOAC, 1990) e cromo (Willians et al., 1962). Ajustou-se às curvas de excreção fecal do indicador, por intermédio do procedimento de Gauss Newton (Souza, 1998), o modelo não-linear, gama 2, tempo-dependente (France et al., 1988):

$$
C_{t}=Z(t-\tau) L^{2} \exp [-L(t-\tau)]
$$

em que: $C_{t}=$ concentração fecal do indicador no tempo "t" (ppm); $\mathrm{t}=$ tempo após o fornecimento do indicador (horas); $\mathrm{L}$ = parâmetro taxa tempo-dependente relativo ao fluxo ruminal de partículas $\left(\mathrm{h}^{-1}\right) ; \mathrm{Z}$ = parâmetro sem interpretação biológica direta (ppm·h); e $\tau=$ tempo decorrido entre a aplicação e o aparecimento do indicador nas fezes (horas).

O tempo médio de retenção total e a excreção fecal foram estimados pelas equações (France et al., 1988):

$$
\begin{aligned}
& T M R T=(2 / L)+\tau \\
& E F=(D / Z) \times 24
\end{aligned}
$$

em que: TMRT $=$ tempo médio de retenção total (horas); EF = excreção fecal $(\mathrm{kg} /$ dia $) ; \mathrm{D}=$ dose de cromo (mg); e L, Z e t como definidos anteriormente.

O consumo voluntário foi estimado utilizando-se como indicador interno a fibra em detergente neutro indigestível (FDNi), determinada nas amostras de suplementos, compostas fecais e extrusas esofágicas, por procedimento de digestibilidade in situ por 144 horas (Lippke et al., 1986).

Em adição, as amostras de suplementos, compostas fecais e extrusas foram avaliadas quanto aos teores de MS, MO, PB, extrato etéreo (EE), cinzas (AOAC, 1990), FDN e fibra em detergente ácido (FDA) (Van Soest \& Robertson, 1985). Os teores totais de compostos nitrogenados não-protéicos (NNP) nas amostras de suplementos e extrusas foram estimados pela diferença entre nitrogênio $(\mathrm{N})$ total e $\mathrm{N}$ precipitável em ácido tricloroacético (Licitra et al., 1996).
O experimento foi analisado em delineamento em quadrado latino balanceado para efeitos residuais de tratamentos (Cochran \& Cox, 1957). As comparações entre níveis de proteína nos suplementos foram conduzidas por decomposição da soma de quadrados de tratamentos em contrastes ortogonais relativos aos efeitos linear, quadrático e cúbico $(\alpha=0,10)$, com subseqüente ajustamento de equações de regressão linear. A SAL destinou-se o mesmo animal, em mesmo piquete, durante todo o período experimental, que foi utilizado como medida de comparação descritiva.

\section{Resultados e Discussão}

O valor médio observado, em termos de PB para a extrusa esofágica, foi de 109,9 g/kg MS (Tabela 3), que foi superior aos limites de 60 e $80 \mathrm{~g} / \mathrm{kg} \mathrm{MS}$, considerados como nível crítico, abaixo do qual comprometeria o funcionamento do ambiente ruminal (Minson, 1990; Van Soest, 1994; Poppi \& McLennan, 1995). Em comparação a relatos para a mesma espécie, observou-se ser este superior ao descrito por Santos (2001) para o período de seca (55 g/kg MS), e próximo ao relatado por Detmann et al. (1999) (99,1 g/kg MS), durante o período de chuvas. Os níveis de FDN (Tabela 3 ) foram inferiores aos relatados para diferentes épocas do ano, normalmente não menores que $700 \mathrm{~g} / \mathrm{kg}$ MS (Detmann et al., 1999; Gomes Jr. et al., 2001; Santos, 2001). Adicionalmente, o teor de FDNi (Tabela 3), ao qual tem-se atribuído alta parcela de efeito de repleção ruminal de forrageiras tropicais (Vieira et al., 1997), foi superior ao relatado por Detmann et al. (1999) (73,7 g/kg MS), para a mesma espécie, durante o período das águas, o que implica, a despeito do menor conteúdo de constituintes da parede celular, em menor degradação potencial destes compostos. Com base nestes resultados, dentro de enfoque simplesmente analítico, pode-se classificar a forragem ingerida pelos animais como de qualidade média a boa.

Embora críticas quanto à contaminação por nitrogênio salivar sejam direcionadas ao método de amostragem da dieta basal (Minson et al., 1976), a comparação dos níveis de NNP com valores relatados em estudo sobre extrusa de bovinos em pastagem tropical, de 5,20 a 13,19\% da PB total para os períodos de seca e águas, respectivamente (Vieira et al., 2000), comprova que, mesmo havendo incremento em função da reciclagem nitrogenada salivar, os níveis de NNP 
Tabela 3 - Composição química de extrusa esofágica e suplementos, com base na matéria seca Table 3 - Chemical composition of esophageal extrusa and supplements, dry matter basis

\begin{tabular}{|c|c|c|c|c|c|c|}
\hline \multirow[b]{2}{*}{ Item $^{1}$} & \multicolumn{2}{|l|}{ Extrusa } & \multicolumn{4}{|c|}{$\begin{array}{l}\text { Suplemento } \\
\text { Supplement }\end{array}$} \\
\hline & $\begin{array}{l}\text { Média } \\
\text { Mean }\end{array}$ & $\mathrm{EPM}^{2}$ & $\begin{array}{c}\mathrm{S} 12 \\
S E M^{2}\end{array}$ & S16 & S20 & S24 \\
\hline $\begin{array}{l}\text { MS (\%) } \\
D M(\%)\end{array}$ & 12,82 & 0,168 & 87,03 & 87,34 & 87,37 & 87,68 \\
\hline $\begin{array}{l}\text { Cinzas }^{3} \\
\text { Ash }^{3}\end{array}$ & 114,3 & 4,527 & 21,6 & 28,6 & 33,4 & 37,6 \\
\hline $\begin{array}{l}\mathrm{MO}^{3} \\
O M^{3}\end{array}$ & 885,7 & 4,527 & 978,4 & 971,4 & 966,6 & 962,4 \\
\hline $\begin{array}{l}\mathrm{PB}^{3} \\
C P^{3}\end{array}$ & 109,9 & 8,832 & 147,0 & 188,2 & 229,9 & 274,0 \\
\hline $\begin{array}{l}\mathrm{NNP}^{4} \\
N P N^{4}\end{array}$ & 39,6 & 1,321 & 50,5 & 51,2 & 56,6 & 52,9 \\
\hline $\begin{array}{l}\mathrm{EE}^{3} \\
E E\end{array}$ & 19,2 & 0,236 & 48,3 & 62,3 & 79,6 & 84,9 \\
\hline $\begin{array}{l}\mathrm{CT}^{3,5} \\
T C^{3,5}\end{array}$ & 756,5 & 10,612 & 783,1 & 720,9 & 657,1 & 603,5 \\
\hline $\begin{array}{l}\mathrm{FDN}^{3} \\
N D F^{3}\end{array}$ & 564,4 & 14,635 & 74,8 & 80,0 & 87,1 & 98,8 \\
\hline $\begin{array}{l}\mathrm{FDNi}^{3} \\
i N D F^{3}\end{array}$ & 121,0 & 8,348 & 6,3 & 5,9 & 7,7 & 6,8 \\
\hline $\begin{array}{l}\mathrm{CNF}^{3,6} \\
N F C^{3,6}\end{array}$ & 192,1 & 5,835 & 708,3 & 640,8 & 570,0 & 504,7 \\
\hline $\begin{array}{l}\mathrm{FDA}^{3} \\
A D F^{3}\end{array}$ & 250,5 & 6,148 & 21,7 & 36,0 & 51,9 & 65,6 \\
\hline
\end{tabular}

${ }^{1}$ MS - matéria seca; MO - matéria orgânica; PB - proteína bruta; NNP - compostos nitrogenados não-protéicos; EE - extrato etéreo; CT - carboidratos totais; FDN - fibra em detergente neutro; FDNi - fibra em detergente neutro indigestível; CNF - carboidratos nãofibrosos; FDA - fibra em detergente ácido.

${ }^{2}$ EPM - erro-padrão da média (SEM - standard error of mean).

${ }^{3} \mathrm{~g} / \mathrm{kg} \mathrm{MS} \mathrm{(g/kg} \mathrm{DM).}$

$4 \%$ dos compostos nitrogenados totais (\% of total nitrogenous compounds).

${ }^{5} \mathrm{CT}=1000-(\mathrm{PB}+\mathrm{EE}+$ Cinzas $)(T C=1000-[C P+E E+A s h])$.

${ }^{6} \mathrm{CNF}=\mathrm{CT}-\mathrm{FDN}(\mathrm{NFC}=\mathrm{TC}-\mathrm{NDF})$.

${ }^{1} D M$ - dry matter. OM - organic matter; $C P$ - crude protein; NPN - non-protein nitrogenous compounds; EE - ether extract; TC - total carbohydrates; NDF - neutral detergent fiber; iDNF - indigestible neutral detergent fiber; NFC - nonfiber carbohydrates; ADF - acid detergent fiber.

relatados neste trabalho (Tabela 3) podem ser atribuídos, em maior parte, à contribuição do NNP da própria forragem, o que é característico em gramíneas tropicais em períodos imediatamente posteriores à ocorrência de chuvas (Poppi \& McLennan, 1995).

Não foram verificados efeitos $(\mathrm{P}>0,10)$ dos níveis protéicos dos suplementos sobre os consumos de MS, MO, MS e MO de forragem e FDN (Tabela 4), que apresentaram valores médios de 28,7 g/kg PV, 26, $1 \mathrm{~g} /$ $\mathrm{kg}$ PV, 18,4 g/kg PV, 16,3 g/kg PV e 11,3 g/kg PV, respectivamente. As proporções médias de volumosos nas dietas consumidas foram de 64,$2 ; 63,8 ; 62,8$ e $61,3 \%$, respectivamente para os tratamentos $\mathrm{S} 12$, S16, S20 e S24.

Em comparação à SAL, observou-se que, com a suplementação, ampliou-se o consumo total de MS, reduzindo-se, no entanto, o consumo de forragem, o que está de acordo com as afirmações de Minson (1990), Obara et al. (1991) e Dixon \& Stockdale (1999). O consumo médio de forragem observado na ausência de fornecimento de suplementos assemelha-se àqueles relatados por Detmann et al. (2001b), em novilhos F1 Limousin x Nelore, em pastagem de Brachiaria decumbens durante o período das águas (23,2 g MS/kg PV), mas foi superior ao relatado por Santos (2001), em novilhos Limousin x Nelore durante o período seco, em pastagem de Brachiaria decumbens $(14,4 \mathrm{~g} \mathrm{MS} / \mathrm{kg} \mathrm{PV})$.

Segundo Obara et al. (1991), em situações em que os suplementos passam a constituir mais de $25 \%$ da dieta total, observa-se redução no consumo total de forragem, comportamento denominado efeito substitutivo. O conhecimento deste efeito apresenta implicações práticas e econômicas (Minson, 1990), 
Tabela 4 - Médias e coeficientes de variação (CV) para os consumos de matéria seca (CMS), matéria orgânica (CMO), matéria seca de forragem (CMSF), matéria orgânica de forragem (CMOF), proteína bruta (CPB), carboidratos totais (CCT), fibra em detergente neutro (CFDN) e carboidratos não-fibrosos (CCNF) e peso vivo médio dos animais (PVM), em função dos diferentes tratamentos

Table 4 - Means and coefficients of variation (CV) for intakes of dry matte (DMI), organic matter (OMI), dry matter from pasture (DMPI), organic matter from pasture (OMPI), crude protein (CPI), total carbohydrates (TCI), neutral detergent fiber (NDFI) and nonfiber carbohydrates (NFCI) and average live weight (ALW) of animals, according to different treatments

\begin{tabular}{|c|c|c|c|c|c|c|c|c|c|}
\hline \multirow[t]{2}{*}{$\begin{array}{l}\text { Variável } \\
\text { Variable }\end{array}$} & \multicolumn{5}{|c|}{$\begin{array}{c}\text { Tratamento } \\
\text { Treatment }\end{array}$} & \multicolumn{3}{|c|}{$\begin{array}{l}\text { Efeito }^{2} \\
\text { Effect }^{2}\end{array}$} & \multirow[t]{2}{*}{$\mathrm{CV}(\%)$} \\
\hline & $\mathrm{SAL}^{1}$ & S12 & S16 & S20 & S24 & $\mathrm{L}$ & $\mathrm{Q}$ & $\mathrm{C}$ & \\
\hline & \multicolumn{9}{|c|}{$\begin{array}{l}\mathrm{kg} / \mathrm{dia} \\
\mathrm{kg} / \text { day }\end{array}$} \\
\hline $\begin{array}{l}\text { CMS } \\
D M I\end{array}$ & $7,8 \pm 1,5$ & 10,0 & 9,8 & 10,0 & 9,5 & $\mathrm{~ns}$ & $\mathrm{~ns}$ & $\mathrm{~ns}$ & 8,9 \\
\hline $\begin{array}{l}\text { CMO } \\
\text { OMI }\end{array}$ & $6,9 \pm 1,3$ & 9,2 & 8,7 & 9,1 & 8,6 & $\mathrm{~ns}$ & $\mathrm{~ns}$ & $\mathrm{~ns}$ & 8,7 \\
\hline $\begin{array}{l}\text { CMSF } \\
D M P I\end{array}$ & $7,8 \pm 1,5$ & 6,5 & 6,3 & 6,5 & 6,0 & $\mathrm{~ns}$ & $\mathrm{~ns}$ & $\mathrm{~ns}$ & 13,8 \\
\hline $\begin{array}{l}\text { CMOF } \\
O M P I\end{array}$ & $6,9 \pm 1,3$ & 5,8 & 5,5 & 5,8 & 5,3 & $\mathrm{~ns}$ & $\mathrm{~ns}$ & $\mathrm{~ns}$ & 13,8 \\
\hline $\begin{array}{l}\mathrm{CPB}^{3} \\
\mathrm{CPI}^{3}\end{array}$ & $0,8 \pm 0,1$ & 1,2 & 1,3 & 1,5 & 1,6 & $* * *$ & $\mathrm{~ns}$ & $\mathrm{~ns}$ & 6,5 \\
\hline $\begin{array}{l}\mathrm{CCT}^{4} \\
\mathrm{TCI}^{4}\end{array}$ & $5,9 \pm 1,2$ & 7,7 & 7,3 & 7,2 & 6,6 & $*$ & $\mathrm{~ns}$ & $\mathrm{~ns}$ & 9,3 \\
\hline $\begin{array}{l}\text { CFDN } \\
N D F I\end{array}$ & $4,4 \pm 0,9$ & 4,0 & 3,8 & 4,0 & 3,7 & $\mathrm{~ns}$ & $\mathrm{~ns}$ & $\mathrm{~ns}$ & 13,0 \\
\hline \multirow[t]{2}{*}{$\begin{array}{l}\mathrm{CCNF}^{5} \\
\mathrm{NFCI}^{5} \\
\end{array}$} & $1,5 \pm 0,3$ & 3,7 & 3,4 & 3,2 & 2,9 & $* * *$ & $\mathrm{~ns}$ & $\mathrm{~ns}$ & 8,1 \\
\hline & \multicolumn{9}{|c|}{$\begin{array}{l}\mathrm{g} / \mathrm{kg} \mathrm{PV} \\
\mathrm{g} / \mathrm{kg} L W\end{array}$} \\
\hline $\begin{array}{l}\text { CMS } \\
D M I\end{array}$ & $22,7 \pm 4,0$ & 28,7 & 29,1 & 29,3 & 27,6 & $\mathrm{~ns}$ & $\mathrm{~ns}$ & $\mathrm{~ns}$ & 7,6 \\
\hline $\begin{array}{l}\text { CMO } \\
O M I\end{array}$ & $20,1 \pm 3,5$ & 26,4 & 26,1 & 26,8 & 25,2 & $\mathrm{~ns}$ & $\mathrm{~ns}$ & $\mathrm{~ns}$ & 7,4 \\
\hline $\begin{array}{l}\text { CMSF } \\
D M P I\end{array}$ & $22,7 \pm 4,0$ & 18,7 & 18,6 & 18,9 & 17,2 & $\mathrm{~ns}$ & $\mathrm{~ns}$ & $\mathrm{~ns}$ & 12,4 \\
\hline $\begin{array}{l}\text { CMOF } \\
O M P I\end{array}$ & $20,1 \pm 3,5$ & 16,6 & 16,5 & 16,7 & 15,2 & $\mathrm{~ns}$ & $\mathrm{~ns}$ & $\mathrm{~ns}$ & 12,4 \\
\hline $\begin{array}{l}\text { CFDN } \\
N D F I\end{array}$ & $12,9 \pm 2,5$ & 11,4 & 11,4 & 11,6 & 10,8 & $\mathrm{~ns}$ & $\mathrm{~ns}$ & $\mathrm{~ns}$ & 11,5 \\
\hline $\begin{array}{l}\mathrm{PVM}^{1,6} \\
A L W^{1,6}\end{array}$ & $339 \pm 10$ & $348 \pm 8$ & $335 \pm 16$ & $337 \pm 19$ & $341 \pm 20$ & - & - & - & - \\
\hline
\end{tabular}

${ }^{1}$ Média e erro-padrão da média (Mean and standard error of mean).

${ }^{2}$ Efeitos linear $(L)$, quadrático $(Q)$ e cúbico $(C)$ em função dos níveis de proteína dos suplementos (Linear [L], quadratic [Q] and cubic [C] effects of the protein levels in the supplements): $\mathrm{ns}-\mathrm{P}>0,10 ;{ }^{*}-\mathrm{P}<0,10 ;{ }^{* *} ; \mathrm{P}<0,05 ; \mathrm{e}^{* * *}-\mathrm{P}<0,01$.

${ }^{3} \hat{Y}=0,7956+0,0343 X\left(r^{2}=0,8813\right)$.

${ }^{4} \hat{Y}=8,6327-0,0796 X\left(r^{2}=0,4317\right)$.

${ }^{5} \hat{Y}=4,4924-0,0653 X\left(r^{2}=0,8938\right)$.

${ }^{6} \mathrm{~kg}$.

sendo desejável que a utilização de suplementos otimize o uso dos recursos forrageiros pelo animal, promovendo mínima substituição. O coeficiente médio de substituição obtido em relação a SAL foi de $0,41 \mathrm{~g}$ MS de forragem/g MS de suplemento, que converge à média de 0,40 relatada por Minson (1990) para forragem com nível protéico médio de $108 \mathrm{~g} / \mathrm{kg}$ MS, próximo ao descrito neste trabalho (Tabela 3). Santos (2001) encontrou, contudo, coeficiente médio de 0,29 ao fornecer suplementos (20\% PB) a novilhos F1 Limousin $\mathrm{x}$ Nelore em nível de 1\% PV durante o período seco. A divergência deste relato em relação à média obtida neste estudo é suportada pela relação diretamente proporcional entre o coeficiente de substituição e a 
qualidade da forragem disponível (Minson, 1990; Dixon \& Stockdale, 1999).

Os consumos de carboidratos totais (CT) e de carboidratos não-fibrosos (CNF) decresceram linearmente $(\mathrm{P}<0,10)$, enquanto o consumo de $\mathrm{PB}$ se elevou linearmente $(\mathrm{P}<0,01)$ com o aumento do nível protéico dos suplementos (Tabela 4). A estes efeitos, uma vez que não foram observadas diferenças entre tratamentos quanto ao consumo de forragem $(\mathrm{P}>0,10)$, atribuise como causa única e exclusiva a variação na composição centesimal dos suplementos, que decresceram em níveis de carboidratos à medida que uréia e soja grão foram acrescidas à composição para elevação do nível protéico (Tabelas 1 e 3).

A ausência de alteração sobre o consumo total e de forragem com a modificação dos níveis protéicos dos suplementos não corresponde a relatos sob condições de forragem de baixa qualidade, nos quais se observam, em média, elevações no consumo de forragem em função de maiores níveis de PB (DelCurto et al., 1990a, b; Hannah et al., 1991). Contudo, Mathis et al. (2000), ao avaliarem o consumo de forragens de média a baixa qualidade, relataram que o consumo não foi estimulado pela suplementação com diferentes níveis de proteína quando o teor protéico da dieta basal foi de $82 \mathrm{~g} / \mathrm{kg} \mathrm{MS}$, embora respostas tenham sido obtidas em níveis inferiores a este.

Respostas sobre o consumo em função de proteína suplementar são, normalmente, inconsistentes quando o conteúdo de nitrogênio na forragem excede 8 a $10 \mathrm{~g} / \mathrm{kg}$ MS (Hess et al., 1994), indicando que a proteína bruta não está tão fortemente relacionada ao consumo em níveis superiores a $70 \mathrm{~g} \mathrm{~PB} / \mathrm{kg}$ MS (Van Soest, 1994). Neste contexto, a falta de relação observada entre nível protéico dos suplementos e consumo permite inferir que a PB não constituiu, ao menos quantitativamente, parâmetro deficitário sobre a dieta basal.
No tocante ao fluxo de partículas, tanto o parâmetro L como o TMRT não foram influenciados pelo nível de proteína bruta dos suplementos $(\mathrm{P}>0,10)$, que apresentaram valores médios de $0,034 \mathrm{~h}^{-1} \mathrm{e} 63,1$ horas, respectivamente. Quanto à SAL, a suplementação permitiu elevação no fluxo de partículas e, conseqüentemente, redução no TMRT (Tabela 5).

Alterações positivas na passagem de partículas no ambiente ruminal são verificadas com o uso de suplementos múltiplos em forragens de baixa qualidade (McCollun \& Galyean, 1985; Guthrie \& Wagner, 1988); no entanto, com a elevação do nível de qualidade da forragem basal, a suplementação gera resultados variáveis, incluindo elevações (Hess et al., 1994) ou estimativas semelhantes às obtidas com animais não-suplementados (Hess et al., 1996; Mathis et al., 2000). Segundo McCollun \& Galyean(1985), a elevação na taxa de passagem de partículas está fortemente relacionada ao aumento no consumo total de MS em função da suplementação, o que justifica a elevação em L observada com o fornecimento de suplementos e a não alteração com a elevação do nível de proteína suplementar, uma vez que não houve alterações sobre o consumo de MS (Tabela 4).

Os valores médios observados para o fluxo de partículas estão abaixo do patamar estabelecido para categoria animal semelhante $\left(0,05 \mathrm{~h}^{-1}\right)($ AFRC, 1993) e de observações em animais manejados em pastagem de Brachiaria decumbens durante o período de chuvas $\left(0,053 \mathrm{~h}^{-1}\right)$ (Detmann et al., 2001b), podendo ser colocados em patamares não condizentes aos níveis de consumo observados (AFRC, 1993).

Os valores de fluxo expressos sob a unidade $\mathrm{h}^{-1}$ indicam a fração do total residente no ambiente ruminal que é deslocada por unidade horária (AFRC, 1993), a qual, quando estimada por indicador de base fibrosa,

Tabela 5 - Médias e coeficientes de variação (CV) relativos a parâmetro taxa relativo ao fluxo ruminal de partículas ("L") ( $\mathrm{h}^{-1}$ ) e tempo médio de retenção total no trato gastrintestinal (TMRT) (horas), em função dos diferentes tratamentos

Table 5 - Means and coefficients of variation (CV) of particulates ruminal flow rate parameter ( $L$ ") $\left(h^{-1}\right)$ and total retention time in gastrintestinal tract (TRT) (hours), according to treatments

\begin{tabular}{|c|c|c|c|c|c|c|c|c|c|}
\hline \multirow[t]{2}{*}{$\begin{array}{l}\text { Variável } \\
\text { Variable }\end{array}$} & \multicolumn{5}{|c|}{$\begin{array}{c}\text { Tratamento } \\
\text { Treatment }\end{array}$} & \multicolumn{3}{|c|}{$\begin{array}{l}\text { Efeito }^{2} \\
\text { Effect }^{2}\end{array}$} & \multirow[t]{2}{*}{$\mathrm{CV}(\%)$} \\
\hline & SAL $^{1}$ & S12 & S16 & S20 & S24 & $\mathrm{L}$ & Q & $\mathrm{C}$ & \\
\hline "L" & $0,029 \pm 0,002$ & 0,034 & 0,033 & 0,034 & 0,034 & $\mathrm{~ns}$ & $\mathrm{~ns}$ & $\mathrm{~ns}$ & 5,1 \\
\hline TMRT (TRT) & $74,1 \pm 5,2$ & 63,5 & 62,9 & 62,4 & 63,6 & $\mathrm{~ns}$ & $\mathrm{~ns}$ & ns & 6,8 \\
\hline
\end{tabular}

${ }^{1}$ Média e erro-padrão da média (Mean and standard error of mean).

${ }^{2}$ Efeitos linear $(L)$, quadrático $(Q)$ e cúbico $(C)$ em função dos níveis de proteína dos suplementos (Linear [L], quadratic [Q] and cubic [C] effects of the protein levels in the supplements): $\mathrm{ns}-\mathrm{P}>0,10$; $^{*}-\mathrm{P}<0,10 ;{ }^{* *} ; \mathrm{P}<0,05 ; \mathrm{e}^{* * *}-\mathrm{P}<0,01$. 
relaciona-se diretamente à cinética de trânsito de componentes dietéticos semelhantes. Esta fração da digesta está diretamente relacionada à capacidade de enchimento do compartimento ruminal, que pode ser ampliada em função da demanda energética do animal (Allen, 1996). Dessa forma, mesmo sob reduções no fluxo fracional, a ampliação na capacidade ruminal poderia, dentro de certos limites, estabelecer fluxo em termos de massa diária semelhante a animais com taxa fracional mais elevada, mas com menor enchimento, permitindo, assim, a manutenção de níveis de consumo condizentes com a demanda produtiva.

\section{Conclusões}

A variação dos níveis protéicos em suplementos múltiplos para terminação de bovinos mestiços no período de transição seca/águas não implica em alterações sobre os parâmetros relacionados ao consumo voluntário e ao fluxo ruminal de partículas. Esse comportamento constitui possível indicativo de quadro de não-deficiência quantitativa de compostos nitrogenados na dieta de animais manejados em condições semelhantes.

\section{Literatura Citada}

AGRICULTURAL AND FOOD RESEARCH COUNCIL AFRC. Energy and protein requirements of ruminants. Wallingford: CAB International, 1993. 159p.

ALLEN, M.S. Physical constraints on voluntary intake of forages by ruminants. Journal of Animal Science, v.74, p.3063$3075,1996$.

ASSOCIATION OF OFFICIAL ANALYTICAL CHEMISTRY - AOAC. Official methods of analysis. 15.ed. Arlington: AOAC International, 1990. 1117p.

COCHRAN, W.G.; COX, G.M. Experimental designs. 2.ed. New York: Jonh Willey \& Sons, 1957.611p.

DelCURTO, T.; COCHRAN, R.C.; HARMON, D.L. et al. Supplementation of dormant Tallgrass-Prarie forage: I. Influence of varying supplemental protein and (or) energy levels on forage utilization characteristics of beef steers in confinement. Journal of Animal Science, v.68, p.515-531, 1990a.

DelCURTO, T.; COCHRAN, R.C.; CORAH, L.R. et al. Supplementation of dormant Tallgrass-Prarie forage: II. Performance and forage utilization characteristics in grazing beef cattle receiving supplements of different protein concentrations. Journal of Animal Science, v.68, p.532542, $1990 \mathrm{~b}$.

DETMANN, E.; PAULINO, M.F.; ZERVOUDAKIS, J.T. et al. Avaliação qualitativa de dois métodos de amostragem de dieta em pastagens de capim braquiária (Brachiaria decumbens Stapf.). In: REUNIÃO ANUAL DA SOCIEDADE BRASILEIRA DE ZOOTECNIA, 36., 1999, Porto Alegre. Anais... Porto Alegre: Sociedade Brasileira de Zootecnia, 1999. p.16.
DETMANN, E.; CECON, P.R.; PAULINO, M.F. et al. Estimação de parâmetros da cinética de trânsito de partículas em bovinos sob pastejo por diferentes seqüencias amostrais. Revista Brasileira de Zootecnia, v.30, p.222-230, $2001 \mathrm{a}$.

DETMANN, E.; PAULINO, M.F.; ZERVOUDAKIS, J.T. et al. Suplementação de novilhos mestiços durante a época das águas: parâmetros ingestivos e digestivos. Revista Brasileira de Zootecnia, v.30, p.1340-1349, 2001 b.

DIXON, R.M.; STOCKDALE, C.R. Associative effects between forages and grains: consequences for feed utilization. Australian Journal of Agricultural Research, v.50, p.75773, 1999.

FRANCE, J.; DHANOA, M.S.; SIDDONS, R.C. et al. Estimating the fecal producing by ruminants from faecal marker concentration curves. Journal of Theoretical Biology, v.135, p.383-391, 1988.

GOMES JR., P.; PAULINO, M.F.; DETMANN, E. et al. Avaliação qualitativa de três métodos de amostragem de dieta em pastagem de capim braquiária (Brachiaria decumbens Stapf.). In: REUNIÃO ANUAL DA SOCIEDADE BRASILEIRA DE ZOOTECNIA, 38., 2001, Piracicaba. Anais... Piracicaba: Sociedade Brasileira de Zootecnia, 2001. p.1132-1134.

GUTHRIE, M.J.; WAGNER, D.G. Influence of protein or grain supplementation and increasing levels of soybean meal on intake, utilization and passage rate of prairie hay in steers and heifers. Journal of Animal Science, v.66, p.1529-1537, 1988

HANNAH, S.M.; COCHRAN, R.C.; VANZANT, E.S. et al. Influence of protein supplementation on site and extent of digestion, forage intake, and nutrient flow characteristics in steers consuming dormant Bluestem-Range forage. Journal of Animal Science, v.69, p.2624-2633, 1991.

HESS, B.W.; PARK, K.K.; KRYSL, L.J. et al. Supplemental protein for beef cattle grazing dormant intermediate wheatgrass pasture: effects on nutrient quality, forage intake, digesta kinetics, grazing behavior, ruminal fermentation, and digestion. Journal of Animal Science, v.72, p.2113-2123, 1994.

HESS, B.W.; KRYSL, L.J.; JUDKINS, M.B. et al. Supplemental cracked corn or wheat bran for steers grazing endophyte-free fescue pasture: effects on live weight gain, nutrient quality, forage intake, particulate and fluid kinetics, ruminal fermentation, and digestion. Journal of Animal Science, v.74, p.1116-1125, 1996.

LENG, R.A. Supplementation of tropical and subtropical pastures for ruminant production. In: GILCHRIST, F.M.C.; MACKIE, R.I. (Eds.) Herbivore nutrition in the subtropics and tropics. Craighall: The Science Press Ltda., 1984. p.129-144.

LICITRA, G.; HERNANDEZ, T.M.; Van SOEST, P.J. Standardization of procedures for nitrogen fractionation of ruminant feeds. Animal Feed Science Technology, v.57, p.347-358, 1996.

LIPPKE, H.; ELLIS, W.C.; JACOBS, B.F. Recovery of indigestible fiber from feces of sheep and cattle on forage diets. Journal of Dairy Science, v.69, p.403-412, 1986.

MATHIS, C.P.; COCHRAN, R.C.; HELDT, J.S. et al. Effects of supplemental degradable intake protein on utilization of medium- to low-quality forages. Journal of Animal Science, v.78, p.224-232, 2000

McCOLLUM, F.T.; GALYEAN, M.L. Influence of cottonseed meal supplementation on voluntary intake, rumen fermentation and rate of passage of prairie hay in beef steers. Journal of Animal Science, v.60, p.570-577, 1985. 
MINSON, D.J. Forage in ruminant nutrition. San Diego: Academic Press, 1990. 483p.

MINSON, D.J.; STOBBS, T.H.; HEGARTY, M.P. et al. Measuring the nutritive value of pasture plants. In: SHAW, N.H.; BRYAN, W.W. (Eds.) Tropical pasture research. Oxford: CAB International, 1976. p.308-338.

NATIONAL RESEARCH COUNCIL - NRC. Nutrient requirements of beef cattle. 6.ed. Washington, D.C.: Academic Press, 1984. 90p.

NATIONAL RESEARCH COUNCIL - NRC. Nutrient requirements of dairy cattle. 7.ed. Washington, D.C.: Academic Press, 2001. 381p.

OBARA, Y.; DELLOW, D.W.; NOLAN, J.V. The influence of energy-rich supplements on nitrogen kinetics in ruminants. In: TSUDA, T.; SASAKI, Y.; KAWASHIMA, R. (Eds.) Physiological aspects of digestion and metabolism in ruminants. New York: Academic Press, 1991. p.515-539.

POPPI, D.P.; McLENNAN, S.R. Protein and energy utilization by ruminants at pasture. Journal of Animal Science, v.73, p.278-290, 1995.

SANTOS, E.D.G. Terminação de bovinos em pastagem de Brachiaria decumbens Stapf, durante a estação seca, alimentados com diferentes concentrados. Viçosa, MG: Universidade Federal de Viçosa, 2001. 163p. Dissertação (Mestrado em Zootecnia) - Universidade Federal de Viçosa, 2001.

SOUZA, G.S. Introdução aos modelos de regressão linear e não-linear. Brasília: EMBRAPA-SPI, 1998. 505p.

UDÉN, P.; COLUCCI, P.E.; Van SOEST, P.J. Investigation of chromium, cerium and cobalt as markers in digesta. Rate of passage studies. Journal of Science and Food Agriculture, v.31, p.625-632, 1980.
Van SOEST, P.J. Nutritional ecology of the ruminant. Ithaca: Cornell University Press, 1994. 476p.

Van SOEST, P.J.; ROBERTSON, J.B. Analysis of forages and fibrous foods. Ithaca: Cornell University, 1985. 202p.

VIEIRA, R.A.M.; PEREIRA, J.C.; MALAFAIA, P.A.M. et al. The influence of elephant-grass (Pennisetum purpureum Schum. Mineiro variety) growth on the nutrient kinetics in the rumen. Animal Feed Science Technology, v.67, p.151161, 1997.

VIEIRA, R.A.M.; PEREIRA, J.C.; MALAFAIA, P.A.M. et al. Fracionamento e cinética de degradação in vitro dos compostos nitrogenados da extrusa de bovinos a pasto. Revista Brasileira de Zootecnia, v.29, p.880-888, 2000.

WILLIANS, C.H.; DAVID, D.J.; IISMA, O. The determination of chromic oxide in faeces samples by atomic absorption spectrophotometry. Journal of Agricultural Science, v.59, p.381-385, 1962.

ZIMMER, A.H.; EUCLIDES FILHO, K. As pastagens e a pecuária de corte brasileira. In: SIMPÓSIO INTERNACIONAL SOBRE PRODUÇÃO ANIMAL SOB PASTEJO, 1997, Viçosa, MG. Anais... Viçosa, MG: Universidade Federal de Viçosa, 1997. p.1-29. 